\title{
Fraction of 1
}

National Cancer Institute

\section{Source}

National Cancer Institute. Fraction of 1. NCI Thesaurus. Code C105484.

A unit for expressing a percentage as a decimal whereby the total value is measured as a fraction of the numeric 1. 